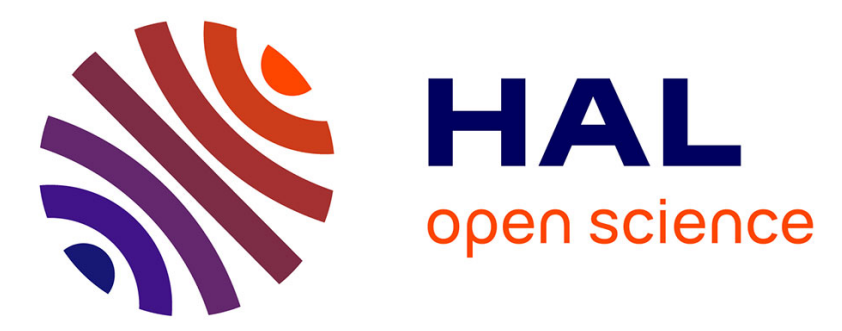

\title{
Poro-micromechanics of materials with complex morphologies - a review, and recent results for concrete, bone, and paper
}

\author{
Christian Hellmich, Viktoria Vass, Markus Königsberger, Mehran Shahidi, \\ Pedro Godinho, Claire Morin, Bernhard Pichler
}

\section{To cite this version:}

Christian Hellmich, Viktoria Vass, Markus Königsberger, Mehran Shahidi, Pedro Godinho, et al.. Poro-micromechanics of materials with complex morphologies - a review, and recent results for concrete, bone, and paper. PoromechanicsVI, Proceeding of the sixth Biot Conference on Poromechanics, Jul 2017, Paris, France. hal-01671733

\section{HAL Id: hal-01671733 \\ https://hal.science/hal-01671733}

Submitted on 22 Dec 2017

HAL is a multi-disciplinary open access archive for the deposit and dissemination of scientific research documents, whether they are published or not. The documents may come from teaching and research institutions in France or abroad, or from public or private research centers.
L'archive ouverte pluridisciplinaire HAL, est destinée au dépôt et à la diffusion de documents scientifiques de niveau recherche, publiés ou non, émanant des établissements d'enseignement et de recherche français ou étrangers, des laboratoires publics ou privés. 


\title{
Poro-micromechanics of materials with complex morphologies - a review, and recent results for concrete, bone, and paper
}

\author{
Christian Hellmich $^{1}$, M.ASCE, F.EMI, Viktoria Vass ${ }^{1}$, Markus Königsberger ${ }^{1}$, Mehran \\ Shahidi $^{1}$, Pedro Godinho ${ }^{1}$, Claire Morin ${ }^{2}$, and Bernhard Pichler ${ }^{1}$, A.M.ASCE \\ ${ }^{1}$ Institute for Mechanics of Materials and Structures, TU Wien - Vienna University of \\ Technology, A-1040 Vienna, Austria; e-mail: christian.hellmich@tuwien.ac.at, \\ viktoria.vass@tuwien.ac.at, markus.koenigsberger@tuwien.ac.at, pedro.godinho@tuwien.ac.at, \\ bernhard.pichler@tuwien.ac.at \\ ${ }^{2}$ Centre for Biomedical Healthcare Engineering, Ecole Nationale Supérieure des Mines, 42023 \\ Saint-Etienne cedex 2, France; e-mail: claire.morin@emse.fr
}

\begin{abstract}
Introduction of infinitely many solid phases in continuum micromechanical representations of hierarchical porous media, in combination with rigorous consideration of free strains and stresses (which arise in the material microstructures as plastic or viscous strains, or as pore pressures) turned out as the major key to providing reliable ("nano-micro-macroscopic" or "micro-mesomacroscopic") structure-mechanical property predictions of complex material systems such as concrete, wood, bone, porous ceramics, or paper.

\section{HIERARCHICAL MICROMECHANICS BASED ON "CLASSICAL" HOMOGENIZATION SCHEMES WITH A FINITE NUMBER OF MATERIAL PHASES}

Since the early 2000's, continuum micromechanics models based on Eshelby's or Laws' elastic matrix-inclusion problems (Eshelby 1975, Laws 1977), such as the classical Mori-Tanaka or self-consistent schemes (Hill 1965a, Mori and Tanaka 1973, Zaoui 2002), have successfully entered the fields of bio and geoengineering; revealing important structure - property relations in materials systems such as concrete (Bernard et al. 2003, Constantinides and Ulm 2004, Hellmich and Mang 2005); bone (Hellmich and Ulm 2002, Hellmich et al. 2004a, Hellmich et al. 2004b, Fritsch and Hellmich 2007, Hamed et al. 2010); and wood (Hofstetter et al. 2005); at length scales ranging from tens of nanometers to a few centimeters. Key to these contributions were hierarchical schemes of representative volume elements (RVEs) consisting of a finite number of ellipsoidally shaped phases. In these schemes, the homogenized elastic properties related to a lower-scale RVE serve as phase properties of a higher-scale RVE; and the smallest appropriate RVE hosts phases with the "universal", i.e. invariant, properties of the material's elementary 
components (in concrete: clinker, water, hydrates, aggregates; in bone: collagen, hydroxyapatite, water with non-collageneous organics; in wood: cellulose, hemicellulose, lignin). However, these "classical" schemes also show considerable limitations; particularly so when it comes to predicting the elastic properties of highly porous systems (as encountered in early-age concrete), to the upscaling of quasi-brittle or ductile strength, or to the representation of one or several pressurized pore phases in interaction with several other phases - where compatibility and equilibrium conditions, in contrast to the two-phase situation (Dormieux et al. 2002), do not allow any more for the derivation of homogenized poromechanical properties.

\section{EXTENDED HOMOGENIZATION SCHEMES FOR INFINITELY MANY, EIGENSTRESSED PHASES}

A standard strategy for tackling the aforementioned challenges lies in resorting to computationally heavy approaches, such as computational homogenization based on the Finite Element method (Kouznetsova et al. 2004), or more recently, statistical physics methods for upscaling from the sub-nanoscale (Pellenq et al. 2009), well up into the so-called mesoscale of coarsed grain approaches of computational chemistry (Ioannidou et al. 2016); i.e. that of several hundreds of micrometers. Quite distinctively, we have, over the last decade, followed an alternative approach characterized by an amazing computational efficiency - and in this way, we have largely extended the number and the scale of inelastic computations which could possibly ever be performed on complex hierarchical material systems. This alternative approach relies on extensions of the "classical" homogenization schemes to more complex microstructures, namely those found in hierarchically organized materials such as concrete, bone, wood, or woodproducts such as paper. What all these extensions have in common, is the introduction of infinitely many, mutually interacting, non-spherical solid phases within one RVE, together with one pore phase reflecting the symmetry of the solid phases' arrangement, e.g. one spherical pore phase with solid phases being oriented uniformly in all space directions. The latter arrangement when realized in a self-consistent setting (Fritsch et al. 2006), has been shown to be highly relevant for the prediction of the porosity - poroelasticity and porosity - strength relations of the extrafibrillar space in bone (Fritsch et al. 2009a), of cement paste (Pichler and Hellmich 2011, Picher et al. 2009, 2013), and of a large collection of various porous polycrystalline ceramics (Fritsch et al. 2009b, 2010, 2013); across the entire range of porosities including very large ones, where the classical, spherical solid phase-based schemes would predict far too high "percolation thresholds". Thereby, homogenization over multi-phase poro-elastic media or over elasto-plastic media requires the extension of the classical concentration problem (the boundary value problem with homogeneous stress or strain boundary conditions prescribed at the boundary of the RVE) towards the consideration of eigenstrains or eigenstresses, plastic strains being a particular choice of the former quantities, and pore pressures of the latter. Therefore, we have generalized Dvorak's transformation field analysis (Dvorak 1992) for the case of arbitrarily shaped eigenstressed phases (Pichler and Hellmich 2010); in this context, the microstrains in each and 
every phase are related to the macroscopic strains imposed on the boundary of the RVE (by means of concentration tensors) and to the free strains occurring in all the other material phases (by means of so-called influence tensors). Introduction of eigenstresses also paves the way to an elegant procedure to upscale viscoelastic properties, as an alternative to the standardly used Laplace-Carson transforms (Laws and McLaughlin 1978, Scheiner and Hellmich 2009). This Carson transform-free procedure was particularly useful for upscaling the viscous behavior of 2D interfaces within an RVE, to overall viscoelastic bulk properties (Shahidi et al. 2014, 2016, Qu et al. 2015). The latter studies have also helped in providing physical interpretations of classical viscoelastic chain model formulations, revealing the springs and dashpots of Kelvin-Voigt chains as being simple functions of matrix elasticity and interface density on the one hand, and of interface size, density, and viscosity on the other (Shahidi et al. 2015a, 2015b).

\section{RECENT RESULTS FOR CONCRETE, BONE, AND PAPER}

As a rule, successful quasi-brittle strength upscaling depends on identification of the appropriate microstress state triggering failure in the weakest phase of the material system. In porous ceramic systems, including the extrafibrillar space of bone, it is already the average stress state in one of the aforementioned, infinitely many phases oriented in all space directions, which appropriately approximates the critical stress state inducing local failure (Fritsch et al. 2009a, 2009b, 2010, 2013). This is due to the pseudo-homogeneous stress states prevailing in needle- or disc-shaped solid material components, which are predominantly loaded axially and/or in shear (but which do not undergo any remarkable bending deformation). The situation changes with material components exhibiting a more complicated nanostructure themselves, such as hydrate gel in cement paste (Pichler and Hellmich 2011, Picher et al. 2009, 2013), or lignin in wood (Bader et al. 2010). In the latter case, the microstresses are not homogeneously distributed across the weakest material phase, and the second-order moments of deviatoric stresses turn out as "effective" microstresses which are actually relevant for irreversible sliding or cracking of the critically loaded material phase. These higher-order microstresses are typically estimated from the homogenized elastic stiffness, through differentiation with respect to the weakest phase stiffness, a concept introduced to poro-micromechanics by (Dormieux et al. 2002).

The situation becomes even more complex in the case of concrete, where the relevant stress peaks in the cement paste matrix occur right at the immediate vicinity of the aggregates, i.e. in the so-called interfacial transition zone (ITZ). While this situation has motivated extensive activity in the field of classical computational mechanics, e.g. based on Rigid Body Spring Networks (Asahina et al. 2011), we have recently derived a fully analytical form of the stress fields throughout the ITZs, by combining the known (homogeneous) stress state inside the aggregates with traction and displacement continuity conditions for the aggregate-to-paste interface, and with the elastic law characterizing the ITZ material itself (Königsberger et al. 2014a, 2014b). These fields, in combination with higher-order downscaling to the hydrate gel level, recently allowed us to successfully upscale one single, "universal" data pair of cohesion 
and internal friction values determined from nanoindentation of hydrates (Sarris and Constantinides 2013), up to the strength evolutions of various cement pastes and mortars at different hydration degrees.

The debate on how to extend elastic to elastoplastic homogenization schemes, has kept the scientific community busy ever since the 1960s. In this context, the most popular ad hoc approach, Hill's incremental method (Hill 1965b), simply replaces the elastic stiffness tensors appearing in the elastic concentration problem alluded to further above, by incremental elastoplastic tangent stiffness tensors. However, it can be readily shown that this approach deviates from the kinematic situation arising with free (and hence, plastic) strains. Consequently, respective homogenized material behaviors turn out as too stiff. Remedy has recently been found (Morin et al. 2017), by extending the aforementioned concentration-influence relations for infinitely many, now elastoplastic solid phases, towards the evolution equations of nonassociated Mohr-Coulomb plasticity, by discretizing the resulting governing equations in time and space, and by solving the latter by means of a new variant of the return mapping algorithm (Clausen et al. 2007). The corresponding homogenized material law was shown to satisfactorily represent the behavior of the porous hydroxyapatite polycrystals making up the so-called cement lines in osteonal bone. This was experimentally validated through strength and ultrasonic tests on hydroxyapatite (Katz and Ukraincik 1971, Akao et al. 1981, Shareef et al. 1993), as well as through mass density, light microscopy, chemical composition, and osteon pushout tests on bone (McCarthy et al. 1990, Bigley et al. 2009, Vuong and Hellmich 2011).

An interesting modification of all the aforementioned developments consists in adapting them for for $2 \mathrm{D}$ networks, i.e. for fibrous phases all lying in a single plane, being in interaction with a spheroidal pore phase with a vanishing thickness-to-diameter ratio. The latter limit case turns out as the main challenge in solving the respective averaging problem based on known analytical solutions for Eshelby-type matrix-inclusion problems. The corresponding remedy appears in the particularly simple form of Hill's morphology tensor for an oblate spheroid of non-zero stiffness, as given by (Sevostianov et al. 2005). This simple mathematical form indeed allows for analytical homogenization over the 2D network; for different non-zero values for the "pore stiffness". Letting the latter go, numerically, towards zero provides the desired result for a homogenized 2D network; which has already undergone a preliminary experimental validation in the case of paper (Godinho et al. 2016): cellulose fiber elasticity (Duncker and Nordman 1965, Page et al. 1977, Ehrnrooth and Kolseth 1984, Adusumalli et al. 2010), was successfully upscaled to the paper sheet level (Alexander and Marton 1968).

\section{REFERENCES}

Adusumalli, R. B., Mook, W. M., Passas, R., Schwaller, P., and Michler, J. (2010). "Nanoindentation of single pulp fibre cell walls." Journal of Materials Science, 45(10), 2558-2563. 
Akao, M., Aoki, H., and Kato, K. (1981). "Mechanical properties of sintered hydroxyapatite for prosthetic applications." Journal of Materials Science, 16(3), 809-812.

Alexander, S. D., and Marton, R. (1968). "Effect of beating and wet pressing on fiber and sheet properties. II. Sheet properties.” Tappi, 51(6), 283-288.

Asahina, D., Landis, E. N., and Bolander, J. E. (2011). "Modeling of phase interfaces during precritical crack growth in concrete." Cement and Concrete Composites, 33(9), 966-977.

Bader, T. K., Hofstetter, K., Hellmich, C., and Eberhardsteiner, J. (2010). "Poromechanical scale transitions of failure stresses in wood: from the lignin to the spruce level." Zeitschrift für Angewandte Mathematik und Mechanik, 90, 750-767.

Bernard, O., Ulm, F. J., and Lemarchand, E. (2003). "A multiscale micromechanics-hydration model for the early-age elastic properties of cement-based materials." Cement and Concrete Research, 33(9), 1293-1309.

Bigley, R. F., Griffin, L. V., Christensen, L., and Vandenbosch, R. (2006). “Osteon interfacial strength and histomorphometry of equine cortical bone." Journal of Biomechanics, 39(9), 1629-1640.

Clausen, J., Damkilde, L., and Andersen, L. (2007). „An efficient return algorithm for nonassociated plasticity with linear yield criteria in principal stress space." Computers \& Structures, 85(23), 1795-1807.

Constantinides, G., and Ulm, F. J. (2004). "The effect of two types of CSH on the elasticity of cement-based materials: Results from nanoindentation and micromechanical modeling." Cement and Concrete Research, 34(1), 67-80.

Dormieux, L., Molinari, A., and Kondo, D. (2002). "Micromechanical approach to the behavior of poroelastic materials." Journal of the Mechanics and Physics of Solids, 50(10), 22032231.

Duncker, B., and Nordman, L. (1965). "Determination of strength of single fibres." PAPER JA PUU-PAPPER OCH TRA, 47(10), 539.

Dvorak, G. J. (1992). "Transformation field analysis of inelastic composite materials." Proceedings of the Royal Society of London A: Mathematical, Physical and Engineering Sciences 437(1900), 311-327.

Ehrnrooth, E. M., and Kolseth, P. (2007). "The tensile testing of single wood pulp fibers in air and in water." Wood and Fiber Science, 16(4), 549-566.

Eshelby, J. D. (1957). "The determination of the elastic field of an ellipsoidal inclusion, and related problems." Proceedings of the Royal Society of London A: Mathematical, Physical and Engineering Sciences 241(1226), 376-396.

Fritsch, A., Hellmich, C., and Young, P. (2013). "Micromechanics-derived scaling relations for poroelasticity and strength of brittle porous polycrystals." Journal of Applied Mechanics, 80(2), 020905.

Fritsch, A., Hellmich, C., and Dormieux, L. (2010). "The role of disc-type crystal shape for micromechanical predictions of elasticity and strength of hydroxyapatite biomaterials." 
Philosophical Transactions of the Royal Society of London A: Mathematical, Physical and Engineering Sciences, 368(1917), 1913-1935.

Fritsch, A., Dormieux, L., Hellmich, C., and Sanahuja, J. (2009b). "Mechanical behavior of hydroxyapatite biomaterials: An experimentally validated micromechanical model for elasticity and strength.” Journal of Biomedical Materials Research Part A, 88(1), 149161.

Fritsch, A., Hellmich, C., and Dormieux, L. (2009a). "Ductile sliding between mineral crystals followed by rupture of collagen crosslinks: experimentally supported micromechanical explanation of bone strength." Journal of Theoretical Biology, 260(2), 230-252.

Fritsch, A., and Hellmich, C. (2007). “'Universal'microstructural patterns in cortical and trabecular, extracellular and extravascular bone materials: micromechanics-based prediction of anisotropic elasticity." Journal of Theoretical Biology, 244(4), 597-620.

Fritsch, A., Dormieux, L., and Hellmich, C. (2006). "Porous polycrystals built up by uniformly and axisymmetrically oriented needles: homogenization of elastic properties." Comptes Rendus Mécanique, 334(3), 151-157.

Godinho, P. M., Wagner, L., Vass, V., Eberhardsteiner, J., and Hellmich, C. (2016). "A continuum micromechanics approach to the elasticity of planar fiber networks and its application to paper." In E-book of World Conference on Timber Engineering, August 22-25., 2016, 2238-2245.

Hamed, E., Lee, Y., and Jasiuk, I. (2010). "Multiscale modeling of elastic properties of cortical bone." Acta Mechanica, 213(1-2), 131-154.

Hellmich, C., and Mang, H. (2005). "Shotcrete elasticity revisited in the framework of continuum micromechanics: from submicron to meter level." Journal of Materials in Civil Engineering, 17(3), 246-256.

Hellmich, C., Ulm, F. J., and Dormieux, L. (2004). "Can the diverse elastic properties of trabecular and cortical bone be attributed to only a few tissue-independent phase properties and their interactions?." Biomechanics and Modeling in Mechanobiology, 2(4), 219-238.

Hellmich, C., Barthélémy, J. F., and Dormieux, L. (2004). "Mineral-collagen interactions in elasticity of bone ultrastructure-a continuum micromechanics approach." European Journal of Mechanics-A/Solids, 23(5), 783-810.

Hellmich, C., and Ulm, F. J. (2002). "Micromechanical model for ultrastructural stiffness of mineralized tissues." Journal of Engineering Mechanics, 128(8), 898-908.

Hill, R. (1965a). "A self-consistent mechanics of composite materials." Journal of the Mechanics and Physics of Solids, 13(4), 213-222.

Hill, R. (1965b). "Continuum micro-mechanics of elastoplastic polycrystals." Journal of the Mechanics and Physics of Solids, 13(2), 89-101.

Hofstetter, K., Hellmich, C., and Eberhardsteiner, J. (2005). "Development and experimental validation of a continuum micromechanics model for the elasticity of wood." European Journal of Mechanics-A/Solids, 24(6), 1030-1053. 
Ioannidou, K., Krakowiak, K. J., Bauchy, M., Hoover, C. G., Masoero, E., Yip, S., Ulm, F. J, Levitz, P., Pellenq, R. J., Del Gado, E. (2016). "Mesoscale texture of cement hydrates." Proceedings of the National Academy of Sciences, 113(8), 2029-2034.

Katz, J. L., and Ukraincik, K. (1971). “On the anisotropic elastic properties of hydroxyapatite.” Journal of Biomechanics, 4(3), 221-227.

Königsberger, M., Pichler, B., and Hellmich, C. (2014a). "Micromechanics of ITZ-aggregate interaction in concrete part I: stress concentration." Journal of the American Ceramic Society, 97(2), 535-542.

Königsberger, M., Pichler, B., and Hellmich, C. (2014b). "Micromechanics of ITZ-Aggregate Interaction in Concrete Part II: Strength Upscaling." Journal of the American Ceramic Society, 97(2), 543-551.

Kouznetsova, V. G., Geers, M. G. D., and Brekelmans, W. A. M. (2004). "Multi-scale secondorder computational homogenization of multi-phase materials: a nested finite element solution strategy." Computer Methods in Applied Mechanics and Engineering, 193(48), 5525-5550.

Laws, N., and McLaughlin, R. (1978). "Self-consistent estimates for the viscoelastic creep compliances of composite materials." Proceedings of the Royal Society of London A: Mathematical, Physical and Engineering Sciences, 359(1697), 251-273.

Laws, N. (1977). "The determination of stress and strain concentrations at an ellipsoidal inclusion in an anisotropic material." Journal of Elasticity, 7(1), 91-97.

McCarthy, R. N., Jeffcott, L. B., and McCartney, R. N. (1990). "Ultrasound speed in equine cortical bone: effects of orientation, density, porosity and temperature." Journal of Biomechanics, 23(11), 1139-1143.

Mori, T., and Tanaka, K. (1973). "Average stress in matrix and average elastic energy of materials with misfitting inclusions." Acta metallurgica, 21(5), 571-574.

Morin, C., Vass, V., and Hellmich, C. (2017). "Micromechanics of elastoplastic porous polycrystals: theory, algorithm, and application to osteonal bone." Under review in International Journal of Plasticity.

Page, D. H., Elhosseiny, F., Winkler, K., and Lancaster, A. P. S. (1977). "Elastic modulus of single wood pulp fibers.” Tappi, 60(4), 114-117.

Pichler, B., Hellmich, C., Eberhardsteiner, J., Wasserbauer, J., Termkhajornkit, P., Barbarulo, R., and Chanvillard, G. (2013). "Effect of gel-space ratio and microstructure on strength of hydrating cementitious materials: An engineering micromechanics approach." Cement and Concrete Research, 45, 55-68.

Pichler, B., and Hellmich, C. (2011). "Upscaling quasi-brittle strength of cement paste and mortar: A multi-scale engineering mechanics model." Cement and Concrete Research, 41(5), 467-476.

Pichler, B., and Hellmich, C. (2010). "Estimation of influence tensors for eigenstressed multiphase elastic media with nonaligned inclusion phases of arbitrary ellipsoidal shape." Journal of Engineering Mechanics, 136(8), 1043-1053. 
Pichler, B., Hellmich, C., and Eberhardsteiner, J. (2009). "Spherical and acicular representation of hydrates in a micromechanical model for cement paste: prediction of early-age elasticity and strength.” Acta Mechanica, 203(3-4), 137-162.

Pellenq, R. J. M., Kushima, A., Shahsavari, R., Van Vliet, K. J., Buehler, M. J., Yip, S., and Ulm, F. J. (2009). "A realistic molecular model of cement hydrates." Proceedings of the National Academy of Sciences, 106(38), 16102-16107.

Qu, T., Verma, D., Shahidi, M., Pichler, B., Hellmich, C., and Tomar, V. (2015). "Mechanics of organic-inorganic biointerfaces - Implications for strength and creep properties." MRS Bulletin, 40(04), 349-358.

Sarris, E., and Constantinides, G. (2013). "Finite element modeling of nanoindentation on C-S$\mathrm{H}$ : Effect of pile-up and contact friction." Cement and Concrete Composites, 36, 78-84.

Scheiner, S., and Hellmich, C. (2009). "Continuum microviscoelasticity model for aging basic creep of early-age concrete.” Journal of Engineering Mechanics, 135(4), 307-323.

Sevostianov, I., Yilmaz, N., Kushch, V., and Levin, V. (2005). "Effective elastic properties of matrix composites with transversely-isotropic phases." International Journal of Solids and Structures, 42(2), 455-476.

Shahidi, M., Pichler, B., and Hellmich, C. (2016). "How interface size, density, and viscosity affect creep and relaxation functions of matrix-interface composites: a micromechanical study.” Acta Mechanica, 227(1), 229-252.

Shahidi, M., Pichler, B., and Hellmich, C. (2015). "Interfacial Micromechanics Assessment of Classical Rheological Models. I: Single Interface Size and Viscosity.” Journal of Engineering Mechanics, 142(3), 04015092.

Shahidi, M., Pichler, B., \& Hellmich, C. (2015). "Interfacial micromechanics assessment of classical rheological models. II: Multiple interface sizes and viscosities.” Journal of Engineering Mechanics, 142(3), 04015093.

Shahidi, M., Pichler, B., and Hellmich, C. (2014). "Viscous interfaces as source for material creep: a continuum micromechanics approach.” European Journal of MechanicsA/Solids, 45, 41-58.

Shareef, M. Y., Messer, P. F., and Van Noort, R. (1993). "Fabrication, characterization and fracture study of a machinable hydroxyapatite ceramic." Biomaterials, 14(1), 69-75.

Vuong, J., and Hellmich, C. (2011). "Bone fibrillogenesis and mineralization: quantitative analysis and implications for tissue elasticity.” Journal of Theoretical Biology, 287, 115 130.

Zaoui, A. (2002). “Continuum micromechanics: survey.” Journal of Engineering Mechanics, 128(8), 808-816. 